University of Nebraska - Lincoln

DigitalCommons@University of Nebraska - Lincoln

Faculty Publications, Department of Psychology

Psychology, Department of

January 2006

\title{
Characterization of nicotine's ability to serve as a negative feature in a Pavlovian appetitive conditioning task in rats
}

Rick A. Bevins

University of Nebraska-Lincoln, rbevins1@unl.edu

Jamie L. Wilkinson

University of Nebraska-Lincoln, wilkinsonjamie@hotmail.com

Matthew I. Palmatier

University of Pittsburgh, mip16@pitt.edu

Hannah L. Siebert

University of Nebraska-Lincoln, hsiebert55@hotmail.com

Steven M. Wiltgen

University of Nebraska-Lincoln, adidaswim1@aol.com

Follow this and additional works at: https://digitalcommons.unl.edu/psychfacpub

Part of the Psychiatry and Psychology Commons

Bevins, Rick A.; Wilkinson, Jamie L.; Palmatier, Matthew I.; Siebert, Hannah L.; and Wiltgen, Steven M., "Characterization of nicotine's ability to serve as a negative feature in a Pavlovian appetitive conditioning task in rats" (2006). Faculty Publications, Department of Psychology. 18.

https://digitalcommons.unl.edu/psychfacpub/18

This Article is brought to you for free and open access by the Psychology, Department of at DigitalCommons@University of Nebraska - Lincoln. It has been accepted for inclusion in Faculty Publications, Department of Psychology by an authorized administrator of DigitalCommons@University of Nebraska - Lincoln. 


\title{
Characterization of nicotine's ability to serve as a negative feature in a Pavlovian appetitive conditioning task in rats
}

\author{
Rick A. Bevins, University of Nebraska-Lincoln \\ Jamie L. Wilkinson, University of Nebraska-Lincoln \\ Matthew I. Palmatier, University of Pittsburgh \\ Hannah L. Siebert, University of Nebraska-Lincoln \\ Steven M. Wiltgen, University of Nebraska-Lincoln
}

\begin{abstract}
Rationale Pavlovian feature negative discriminations have been widely used to understand inhibitory conditioning processes using exteroceptive stimuli. Comparatively little is known about inhibitory conditioning processes using a drug state as a negative feature. A negative feature signals that presentation of a conditional stimulus (CS) will not be paired with an unconditioned stimulus. Objectives: The present research examined whether nicotine served as a negative feature and started characterizing its properties. Methods and results: In acquisition, rats received intermixed saline and nicotine $(0.4 \mathrm{mg} / \mathrm{kg}$, base) sessions. On saline sessions, a 15-s light CS was paired with 4-s access to sucrose; the CS was presented on nicotine sessions, but sucrose was withheld. The discrimination was acquired with more goal tracking during the CS on saline sessions. Nicotine's inhibition of this conditioned response $(\mathrm{CR})$ was sensitive to nicotine dose $\left(\mathrm{ED}_{50}=0.225\right)$ and injection to testing interval (CR returned at $200 \mathrm{~min}$ ). Mecamylamine pretreatment, but not hexamethonium, produced a loss of inhibitory control by nicotine suggesting a role for central nicotinic acetylcholine receptors. Amphetamine, bupropion, arecoline, and chlordiazepoxide, but not caffeine, substituted for the nicotine feature. However, in locomotor tests, amphetamine and bupropion increased activity; arecoline and chlordiazepoxide decreased activity. For this reason, the motor effects of these ligands could not be dissociated from substitution via shared stimulus properties. Conclusions: This feature negative task provides a preclinical model for studying how drug states inhibit responding, although identifying the process(es) mediating CR inhibition will require further research.
\end{abstract}

Keywords: Amphetamine, Arecoline, Bupropion, Caffeine, Chlordiazepoxide, Classical conditioning, Conditioned inhibition, Drug discrimination, Nicotinic acetylcholine receptors, Smoking, Tobacco

Submitted: December 2004; accepted: May 2005; published online: July 2005.

\section{Introduction}

The interoceptive cues induced by a drug can come to guide behavior. The most widely studied example of this behavioral control is the operant drug discrimination task. In this task, the drug state, referred to as a discriminative stimulus $\left(\mathrm{S}^{\mathrm{D}}\right)$, signals that a response will be reinforced. The absence of drug cues nonreinforcement of the same response (Colpaert 1986). Nicotine, the primary addictive constituent of tobacco, can serve as an $\mathrm{S}^{\mathrm{D}}$ in human and nonhuman animals. For example, rats can learn that one response, left-lever presses, will be reinforced with a food pellet when nicotine $(0.4 \mathrm{mg} / \mathrm{kg}$, s.c. $)$ is administered before the session; an alternative response (pressing right lever) has no consequence. In contrast, when saline is administered, the rightlever press will be reinforced (Stolerman 1989). In this two- lever discrimination task, nicotine comes to prompt mostly left-lever pressing. Conversely, nicotine can also be considered a signal for nonreinforcement for right-lever pressing $\left(\mathrm{S}^{\Delta}\right)$ resulting in inhibition of responding (Honig et al. 1963). Troisi (2003) recently showed that nicotine could function only as an $\mathrm{S}^{\Delta}$. In this one-lever drug discrimination task, responding was reinforced on a variable interval 1-min schedule on saline sessions; nicotine $(0.2 \mathrm{mg} / \mathrm{kg}$, i.p.) occasioned nonreinforcement. Responding was withheld only in the nicotine state.

There is a substantial literature on nicotine as an $\mathrm{S}^{\mathrm{D}}$ in this operant drug discrimination task. In contrast, there is relatively little research examining the cueing effects of nicotine in a Pavlovian discrimination task. Arguably, in a Pavlovian conditioning task, a positive feature is the procedural 
equivalent to an $\mathrm{S}^{\mathrm{D}}$ (cf. Davidson et al. 1988). A drug state is a positive feature if it sets the occasion upon which another stimulus (i.e., conditional stimulus or CS) is paired with an unconditioned stimulus (US). We have shown that nicotine serves as a positive feature in an appetitive discrimination task with rats (Palmatier et al. 2004, 2005; Sanderson et al. 2003). In that research, a brief light CS was presented several times in daily 20 -min sessions. On nicotine sessions $(0.4 \mathrm{mg} / \mathrm{kg})$, the light CS was followed by 4 -s access to a sucrose solution in a dipper receptacle. No sucrose was delivered if saline was administered. Differential control by the CS of head entries into the dipper, hereafter termed goal tracking, is a widely used measure of Pavlovian conditioned responding (Bouton and Sunsay 2003; Delamater 1995; Rescorla 1999) and refers to a rat's tendency to search places where rewards have occurred (Boakes 1977; Farwell and Ayres 1979). The light CS evoked more goal tracking in the nicotine state than the saline state, indicating that nicotine served as a positive feature [see Parker et al. 1994 and Miller et al. 2002 for examples of Pavlovian drug discriminations using pigeon sign tracking (autoshaping) with methadone or phencyclidine as a drug feature].

Drug states may also function as a negative feature in a Pavlovian discrimination task. A negative feature signals that the CS will not be paired with the US (cf. S ${ }^{\Delta}$ ). For example, Troisi and Akins (2004) using a sexual conditioning task reported that cocaine $(10 \mathrm{mg} / \mathrm{kg})$ served as a negative feature. That is, male quail were administered either cocaine or saline. On saline sessions, entrance of a wood block (the CS) into the apparatus signaled copulatory opportunity with a female (the US). On cocaine sessions, the wood block CS was presented but was not followed by the US. Conditioning was evidenced by male quail approaching the vicinity where the CS was presented on past conditioning trials only in the saline state (i.e., sign tracking).

Maes and Vossen (1997) attempted to establish amphetamine $(0.5 \mathrm{mg} / \mathrm{kg})$ or midazolam $(0.1 \mathrm{mg} / \mathrm{kg})$ as a negative feature in rats using a goal-tracking task similar to the one described earlier (cf. Palmatier et al. 2005). In the Maes and Vossen study, the drug state signaled that 30-s illumination of a light within a food magazine was not followed by a food pellet; in the saline state, the same light CS was followed by food. After training (i.e., 20 reinforced and 20 nonreinforced light trials), extinction tests were conducted to assess stimulus control. Relative to saline, neither amphetamine nor midazolam prompted less goal tracking during the light CS indicating that neither drug served as a negative feature for withholding goal tracking.

For several reasons, this failure probably does not reflect a fundamental difference between sign tracking vs goal tracking, quail vs rats, copulatory opportunity vs food, or cocaine vs amphetamine or midazolam. First, nicotine can serve as an $\mathrm{S}^{\Delta}$ for food-reinforced lever pressing in rats (Troisi 2003). Second, drug states can serve as negative features in aversive Pavlovian conditioning tasks. For example, Jaeger and $\mathrm{Mu}-$ cha (1990) pretreated rats with fentanyl $(0.04 \mathrm{mg} / \mathrm{kg}$, s.c. $)$ or saline before access to a novel taste (the CS). On saline sessions, the taste CS was followed by an illness-inducing injection of $\mathrm{LiCl}$ (the US). On fentanyl sessions, taste was not followed by $\mathrm{LiCl}$. Rats consumed more of the taste CS on drug than saline sessions indicating that fentanyl served as a negative feature inhibiting the avoidance $\mathrm{CR}$. Third, nicotine can serve as a CS- in a Pavlovian drug discrimination task (Besheer et al. 2004). In that study, saline signaled intermittent access to liquid sucrose (CS+); nicotine $(0.4 \mathrm{mg} / \mathrm{kg}$, s.c.) signaled the absence of sucrose (CS-). In contrast to the drug feature research, there were no discrete cues in either session type. Rats learned the discrimination with more goal tracking in saline than in nicotine sessions.

The main goal of the present research was to determine whether nicotine could serve as a negative feature in a goaltracking task. Such a demonstration is important. The bulk of research on drug states has focused on facilitation of behavior. Development of a feature negative task would provide the field with a tool for studying how drug states inhibit conditioned responding. Because nicotine functioned as a negative feature, an additional goal was to provide an initial characterization (duration, antagonism, substitution, generalization) of nicotine in this role. In substitution tests, arecoline, a muscarinic acetylcholine receptor agonist, and chlordiazepoxide (CDP), a $\mathrm{GABA}_{\mathrm{A}}$ agonist, were selected because their $\mathrm{S}^{\mathrm{D}}$ properties differ from nicotine (Schechter and Rosecrans 1972; Stolerman et al. 1984). Nicotine has stimulant properties in rats (Bevins and Palmatier 2003); thus, caffeine and D-amphetamine were selected for their stimulant actions. Finally, bupropion was of interest given its use as a smoking cessation aid (Zyban) and recent evidence showing substitution for the cueing effects of nicotine (Besheer et al. 2004; Young and Glennon 2002).

\section{Materials and methods}

Animals Twenty-one male Sprague-Dawley rats from Harlan (Indianapolis, IN) were housed separately in polycarbonate tubs lined with wood shavings in a temperatureand humidity-controlled colony. Water was available continuously in the colony, but access to chow was restricted so that rats were maintained at $85 \%$ of their free-feeding weight ( $375 \pm 8 \mathrm{~g})$. This $85 \%$ weight was adjusted by $2 \mathrm{~g}$ approximately every 30 days. All experimental sessions were conducted during the light portion of a 12:12 h light/dark cycle. Experimental protocols were approved by the University of Nebraska-Lincoln IACUC and followed the "Guide for the Care and Use of Laboratory Animals" (National Research Council 1996).

Apparatus Each of the seven conditioning chambers (ENV-008CT; Med Associates, Georgia, VT) had clear polycarbonate ceiling, front wall, and back wall; sidewalls were aluminum. On the bottom center of one sidewall was a $5.2 \times 5.2 \mathrm{~cm}$ opening to a recessed dipper receptacle. Sucrose 


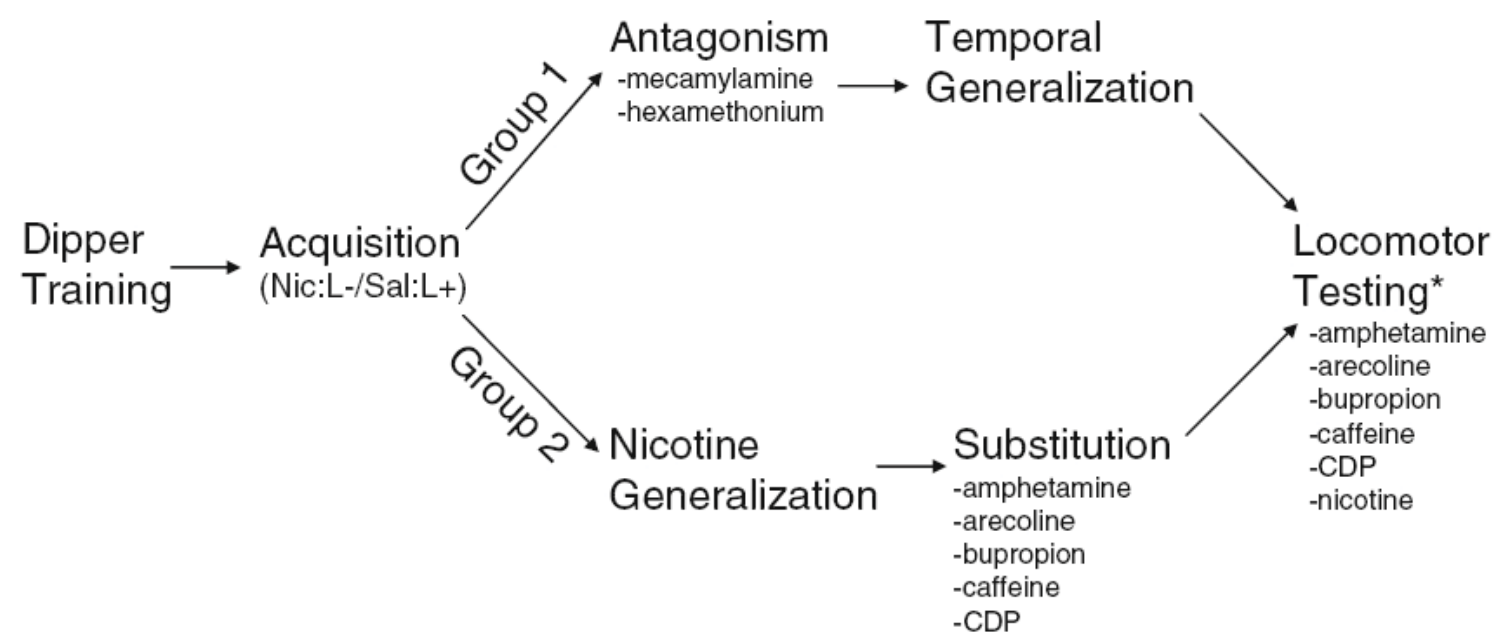

Fig. I This shows a flow chart of the methods for each group.All rats received dipper training followed by Pavlovian drug discrimination in which nicotine (Nic) signaled the absence of reinforcement following presentation of the I5-s light CS (L-). The light CS was followed by 4-s access to a sucrose solution $(L+)$ on saline ( $\mathrm{Sal}$ ) sessions. For group I $(n=7)$, antagonism of the nicotine negative feature was assessed before testing the effects of the injection to placement interval. For group $2(n=\mid 4)$, a nicotine generalization function was obtained before substitution of various doses of the listed ligands. Testing of the locomotor effects of the listed ligands was conducted following completion of temporal generalization (group I) or substitution (group 2).

*Only a subset of rats from each group was tested (see main text for details)

solution $(26 \% \mathrm{w} / \mathrm{v})$ was delivered via a $0.1-\mathrm{ml}$ cup attached to a dipper arm. An infrared unit, located $1.2 \mathrm{~cm}$ within the receptacle and $3 \mathrm{~cm}$ from the floor, detected head entries. Mounted above $(6 \mathrm{~cm})$ and to either side of the top edge of the dipper were two white cue lights $(28 \mathrm{~V}, 100 \mathrm{~mA})$. Illumination of the lights for $15 \mathrm{~s}$ served as the CS. Each chamber was housed in a sound-attenuating cubicle fitted with a fan to provide airflow and masking noise. A personal computer with Med Associates interface and software controlled stimulus events and recorded dipper entries. Activity was measured in chambers made of white PVC pipe (30.5-cm diameter). Each chamber was divided into four equal sections by two infrared units positioned $4 \mathrm{~cm}$ above the wire mesh floor. Activity was defined as the number of beam breaks recorded by a computer.

Drugs (-)Nicotine hydrogen tartrate, mecamylamine hydrochloride, hexamethonium sulfate, arecoline hydrochloride, D-amphetamine sulfate, chlordiazepoxide hydrochloride, bupropion hydrochloride, and caffeine anhydrous (Sigma, St. Louis, MO) were dissolved in saline $(0.9 \% \mathrm{NaCl})$. Nicotine was brought to a $\mathrm{pH}$ of $7.0 \pm 0.2$ with a dilute $\mathrm{NaOH}$ solution. Nicotine, arecoline, mecamylamine, and hexamethonium were administered via subcutaneous (s.c.) injection at a volume of $1 \mathrm{ml} / \mathrm{kg}$. All other compounds except caffeine were injected intraperitoneally (i.p.) at the same volume; caffeine was administered i.p. at $2 \mathrm{ml} / \mathrm{kg}$. Nicotine doses are expressed as the base form; all other drug doses are expressed as the salt form. Injection route, as well as injection to placement interval and doses (see later), was based on past nicotine drug discrimination research (cf. Palmatier et al. 2005; Stolerman et al. 1984; Young and Glennon 2002).

\section{General procedures}

Dipper training and acquisition For 3 days (ca. $50 \mathrm{~min} /$ day), rats were trained to access sucrose within 4 s. Sucrose deliveries were controlled by a probability function that began at 0.167 per $4 \mathrm{~s}$ and decreased to 0.05 per $4 \mathrm{~s}$ over three sessions. This training regime resulted in robust dipper-entry behavior for all rats. In acquisition, rats received a s.c. nicotine $(0.4 \mathrm{mg} / \mathrm{kg})$ or saline injection $5 \mathrm{~min}$ before the start of a session. On saline sessions, the offset of each of the eight 15-s light CS presentations was followed by 4$\mathrm{s}$ access to sucrose. Nicotine sessions were similar except CS offset was followed by a 4-s "empty interval" (i.e., no sucrose). Acquisition consisted of 8-day cycles that included four nicotine and four saline sessions. Session order was randomly determined with the restriction that no more than two of a session type could occur consecutively in a cycle. Sessions lasted about $20 \mathrm{~min}$. The time before onset of the first CS varied from 90 to $180 \mathrm{~s}$ (mean $135 \mathrm{~s}$ ) with time between sucrose offset and the next CS onset varying from 75 to $165 \mathrm{~s}$ (mean $120 \mathrm{~s}$ ). Rats received 12 nicotine and $12 \mathrm{sa}-$ line sessions before testing.

Testing Rats were assigned to one of two groups before testing: group $1(n=7)$ or group $2(n=14)$. Groups differed only in what variable was assessed on test days (see Fig. 1 for a diagram of the methods). For testing, cycles were shifted from 8 to 7 days; each cycle included three nicotine and three saline training sessions followed by a test session. Training sessions were identical to those in acquisition, and data from these sessions were used to determine whether a rat met performance criteria for testing (see later). Rats that did not meet criteria remained in the home cage on the 
test day. During the 4-min test session, rats received a single presentation of the 15-s light CS; sucrose was withheld on test days. The time between the start of the test session and onset of the CS varied as in the acquisition phase.

\section{Specific procedures: group 1}

Antagonism The 7-day testing cycle started immediately after acquisition training. On the test day, rats that met criteria were treated with the central and peripheral nicotinic acetylcholine receptor (nAChR) antagonist mecamylamine $(0.5$ or $1 \mathrm{mg} / \mathrm{kg}$; Martin et al. 1989$)$, the peripheral nAChR antagonist hexamethonium (2.5 or $5 \mathrm{mg} / \mathrm{kg}$; Asghar and Roth 1971), or saline s.c. 20 min before the start of the session. As in training, nicotine $(0.4 \mathrm{mg} / \mathrm{kg})$ was injected $5 \mathrm{~min}$ before the test. Each rat was tested with each solution in random order. Upon completion of that order, a new random order was tested.

Injection to testing interval Upon completion of the antagonism tests, the 7-day cycle continued, but on the test day, rats were injected with the nicotine training dose and then placed in the test chamber after $0,5,50,100$, or $200 \mathrm{~min}$ had elapsed from injection. Each rat was tested at each interval in random order. Upon completion of that sequence, a new random order was tested. Once both sequences were completed, one additional interval was tested. In that test, rats were injected with nicotine, immediately placed in the chamber, and the CS onset occurred $15 \mathrm{~s}$ after the start of the session rather than the typical 90-180 s.

\section{Specific procedures: group 2}

Nicotine generalization On the test day, rats that met criteria were tested with saline or one of six doses of nicotine $(0.01,0.03,0.05,0.1,0.2$, or $0.4 \mathrm{mg} / \mathrm{kg})$. Nicotine was injected $5 \mathrm{~min}$ before the start of the 4-min test session. Each rat was tested once with each solution in random order.

Substitution Upon completion of generalization, substitution of the following ligands was assessed: arecoline (0.375, 0.75, $1.5 \mathrm{mg} / \mathrm{kg})$, bupropion $(5,10,20,30 \mathrm{mg} / \mathrm{kg})$, caffeine $(5,10,30 \mathrm{mg} / \mathrm{kg}), \operatorname{CDP}(2.5,5,10 \mathrm{mg} / \mathrm{kg})$, or Damphetamine $(0.125,0.25,0.5,1 \mathrm{mg} / \mathrm{kg})$. Arecoline was injected s.c. 5 min before testing; the remaining ligands were injected i.p. 15 min before testing. A random order was generated at the start of substitution testing for each rat, but when an additional dose of a ligand was added due to preliminary results, that dose was inserted randomly into the remaining sequence. One rat in group 2 displayed atypical behaviors in the home cage in this phase. It was given free access to food and did not continue in the experiment. Accordingly, data from this rat were excluded from analyses and graphs for this phase.

\section{Locomotor assessment}

The locomotor effects of ligands used in substitution testing were assessed once rats finished in the discrimination task. First, rats were exposed to the locomotor chamber for $30 \mathrm{~min}$ on three consecutive days to reduce novelty-induced activity. On the following day, each rat was exposed to the locomotor chamber for $10 \mathrm{~min}$ and then returned to the home cage. The assigned ligand was then administered, and the rat was returned to the chamber after the injection to placement interval used in substitution testing. Locomotor activity was collected for $10 \mathrm{~min}$. We analyzed and plotted activity counts from the first $4 \mathrm{~min}$ because this time reflects the duration of substitution tests. This procedure was repeated daily until all assigned ligands were tested. A subset of rats from groups 1 and $2(n=12)$ were tested with saline, $0.4 \mathrm{mg} / \mathrm{kg}$ nicotine, $1 \mathrm{mg} / \mathrm{kg}$ amphetamine, $20 \mathrm{mg} / \mathrm{kg}$ bupropion, $10 \mathrm{mg} / \mathrm{kg}$ CDP, and $1.5 \mathrm{mg} / \mathrm{kg}$ arecoline. A different subset of rats $(n=7)$ was tested with saline, $0.2 \mathrm{mg} / \mathrm{kg}$ nicotine, 10 and $30 \mathrm{mg} / \mathrm{kg}$ caffeine, and $0.75 \mathrm{mg} / \mathrm{kg}$ arecoline. Each rat remained at its $85 \%$ weight and was assigned a unique drug order for testing.

\section{Discrimination criteria and data analyses}

Dipper entries were converted to elevation and duration scores. The elevation score was defined as the number of entries during the 15-s light CS minus the entries in the 15-s interval immediately before CS onset (pre-CS period). The duration score was defined as the time the head was in the dipper during the CS minus the duration during the preCS period. The elevation score served as the main dependent measure because it allows comparison with previously published research on drug features (Palmatier et al. 2004, 2005), and the data pattern was similar for each measure making presentation of duration scores redundant. We also analyzed the pre-CS dipper entry rates to determine whether baseline levels of dipper entries changed with tests. Before testing, each rat was required to meet two criteria. (1) The mean elevation or duration score for nicotine sessions were subtracted from corresponding saline sessions score. Testable performance was defined as a mean difference score $\geq 3$ for elevation score or a mean difference score $\geq 2 \mathrm{~s}$ for duration score. (2) A similar contrast was conducted on first trial elevation and duration scores for the last nicotine and saline training sessions; the difference had to be positive (cf. Palmatier et al. 2004, 2005).

When a rat was tested twice on the same variable (see group 1), a single value for analysis was derived by taking an average for each rat. Omnibus tests were one or two-way repeated measures analyses of variance (ANOVA). Post hoc comparisons prompted by a significant $F$ value used Tukey's HSD tests to control for type I error rate. These comparisons were limited to contrasting each test value to a 
saline and/or nicotine comparison condition. Statistical significance was declared using a two-tailed rejection region of 0.05 for all tests. The median effective dose $\left(E_{50}\right)$ was calculated using linear regression on doses from the ascending limb of the dose-effect function. Locomotor activity for each test dose was compared to saline using $t$-tests.

\section{Results}

Acquisition: all rats The feature negative discrimination was readily acquired with goal tracking in the saline state increasing across early sessions (Fig. 2). There was a main effect of Drug and Session $\left(F{ }^{\prime} \mathrm{s} \geq 21.32, p\right.$ 's $\left.<0.001\right)$ and a significant Drug $\times$ Session interaction $[F(11,220)=21$. 82 , $p<0.001, \mathrm{MSE}=1.55]$. Elevation scores were significantly different from session 2 to 12 [minimum mean difference $\left.\left(\mathrm{mmd}_{\mathrm{hsd}}\right)=0.76\right]$. For pre-CS dipper entries in the last two nicotine and two saline sessions, neither the Drug nor the Drug $\times$ Session interaction was significant $(F ' s<1)$, indicating similar baseline levels of dipper entries (see Table 1).
Group 1: nAChR antagonism Pretreatment with mecamylamine, but not hexamethonium, blocked nicotine's ability to serve as a negative feature (Fig. 3a). The saline pretreatment data (leftmost bar) were included in each of the following ANOVAs. The ANOVA for hexamethonium was not significant $(F<1)$. In contrast, the ANOVA for mecamylamine was significant $[F(2,12)=12.94, p=0.001, \mathrm{MSE}=3.20]$ with both doses of mecamylamine increasing goal tracking relative to saline pretreated controls $\left(\mathrm{mmd}_{\mathrm{hsd}}=2.55\right)$. These $\mathrm{nAChR}$ antagonists did not affect dipper entry rates during the pre-CS period ( $F$ 's $<1$; see Table 1$)$.

Injection to testing interval Nicotine lost its function as a negative drug feature as time increased between nicotine injection and placement into the conditioning chamber (Fig. 3b). The ANOVA was significant $[F(4,24)=15.85$, $p<0.001, \mathrm{MSE}=3.14]$, with the 200-min interval differing from 5-min training delay $\left(\mathrm{mmd}_{\mathrm{hdd}}=2.83\right)$. Dipper entry rates during the pre-CS period did not vary significantly as a function of test interval, $[F(4,24)=1.63, p=0.20$; Table 1].

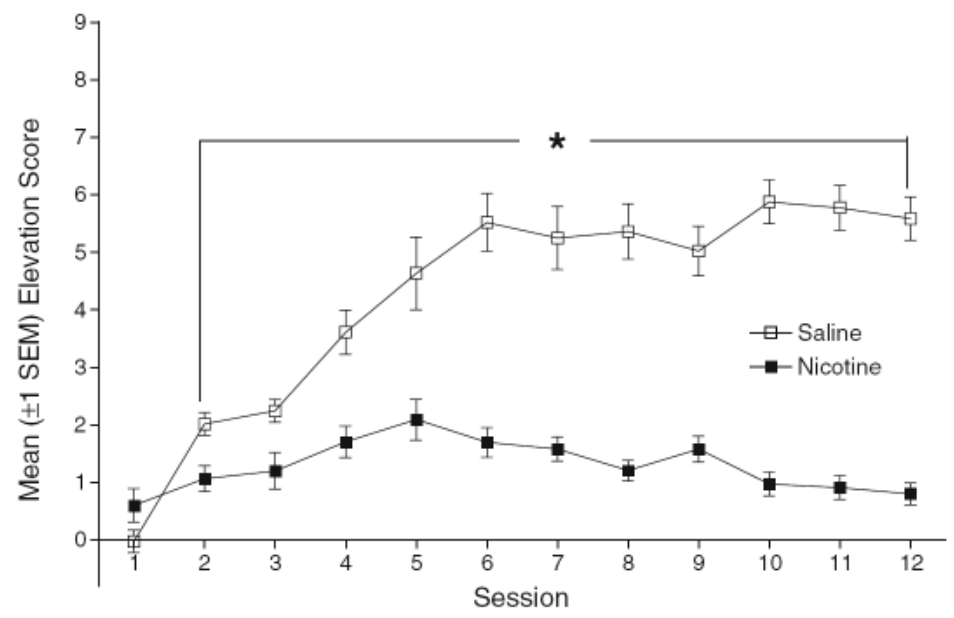

Fig. 2 Mean elevation score ( \pm I SEM) for nicotine and saline sessions for all rats in the acquisition phase. Bracket with asterisk denotes significant difference $(p<0.05)$ between sessions 2 to 12

Table 1 Pre-CS and CS dipper entries ( \pm 1 SEM) for acquisition and group 1

\section{Acquisition}

\begin{tabular}{lllll} 
& \multicolumn{2}{c}{ Nicotine } & \multicolumn{2}{c}{ Saline } \\
Pre-CS & Session 11 & Session 12 & $1.52( \pm .21)$ & $1.60( \pm .17)$ \\
CS & $0.84( \pm .12)$ & $0.92( \pm .12)$ & $7.26( \pm .36)$ & $7.45( \pm .39)$
\end{tabular}

nAChR Antagonism (mg/kg)

$\begin{array}{llllll} & \text { Saline } & 2.5 \mathrm{Hex} & 5.0 \mathrm{Hex} & 0.5 \mathrm{Mec} & 1.0 \mathrm{Mec} \\ \text { Pre-CS } & 0.86( \pm .40) & 0.88( \pm .34) & 1.14( \pm .42) & 0.64( \pm .32) & 1.43( \pm .47) \\ \text { CS } & 1.14( \pm .46) & 1.14( \pm .18) & 1.29( \pm .51) & 3.43( \pm .46) & 6.86( \pm 1.01)\end{array}$

Injection to Placement Interval (min)

\begin{tabular}{lllllll} 
& 0 & 5 & 50 & 100 & 200 & Immediate \\
\cline { 2 - 6 } Pre-CS & $0.93( \pm .20)$ & $0.79( \pm .29)$ & $1.07( \pm .25)$ & $0.21( \pm .15)$ & $1.07( \pm .40)$ & $0.57( \pm .37)$ \\
CS & $1.27( \pm .29)$ & $1.71( \pm .43)$ & $2.79( \pm .58)$ & $4.71( \pm 1.25)$ & $7.93( \pm .97)$ & $2.43( \pm .84)$
\end{tabular}


The rightmost bar in Fig. 3b shows the additional test data in which rats received the light CS $15 \mathrm{~s}$ after nicotine and placement into the chamber. The elevation score and pre-CS dipper entries for this test delay did not differ statistically from the 5-min value $(t$ 's $<1)$.

Group 2: nicotine generalization Elevation scores increased as the dose of the nicotine feature was decreased from the $0.4-\mathrm{mg} / \mathrm{kg}$ training dose $[F(6,78)=5.71$, $p<0.001, \mathrm{MSE}=5.89$; Fig. 4a]. The 0.03 - to $0.1-\mathrm{mg} / \mathrm{kg}$ doses were significantly higher than the nicotine training dose $\left(\mathrm{mmd}_{\mathrm{hsd}}=2.67\right)$. Further contrasts revealed that goal tracking was significantly lower than saline levels only at the $0.4-\mathrm{mg} /$ $\mathrm{kg}$ dose. The $\mathrm{ED}_{50}$ for the nicotine feature was $0.225 \mathrm{mg} / \mathrm{kg}$. Dipper entry rates during the pre-CS period did not vary as a function of nicotine dose $[F(6,78)=1.02, p=0.419$; Table 2].

Substitution tests Goal tracking decreased as the dose of amphetamine increased $[F(3,36)=4.57, p=0.008$, $\mathrm{MSE}=10.34]$, suggesting substitution for the nicotine feature. The $0.125-0.25 \mathrm{mg} / \mathrm{kg}$ amphetamine doses controlled more goal tracking than nicotine $\left(\mathrm{mmd}_{\mathrm{hsd}}=3.43\right.$; Fig. $\left.4 \mathrm{~b}\right)$. Only the $1-\mathrm{mg} / \mathrm{kg}$ dose of amphetamine differed significantly from the saline comparison. The $\mathrm{ED}_{50}$ for amphetamine was $0.562 \mathrm{mg} / \mathrm{kg}$. Bupropion displayed a pattern similar to amphetamine $[F(3,36)=16.77, p<0.001, \mathrm{MSE}=6.55]$. Elevation
Fig. 3 a Mean elevation score ( \pm I SEM) for the nicotinic acetylcholine antagonism tests for rats in group I. Saline (SAL), hexamethonium, and mecamylamine were administered 20 min before the start of the test (I 5 min before nicotine). Asterisks denote significant difference from saline pretreatment condition, $p<0.05$. b Mean elevation score for the temporal delay tests for rats in group I. The rightmost bar is from a follow-up test in which rats were placed immediately into the chamber after nicotine injection and the light CS was tested I5 s after placement. Asterisk denotes significant difference from the training delay (5 min), $p<0.05$
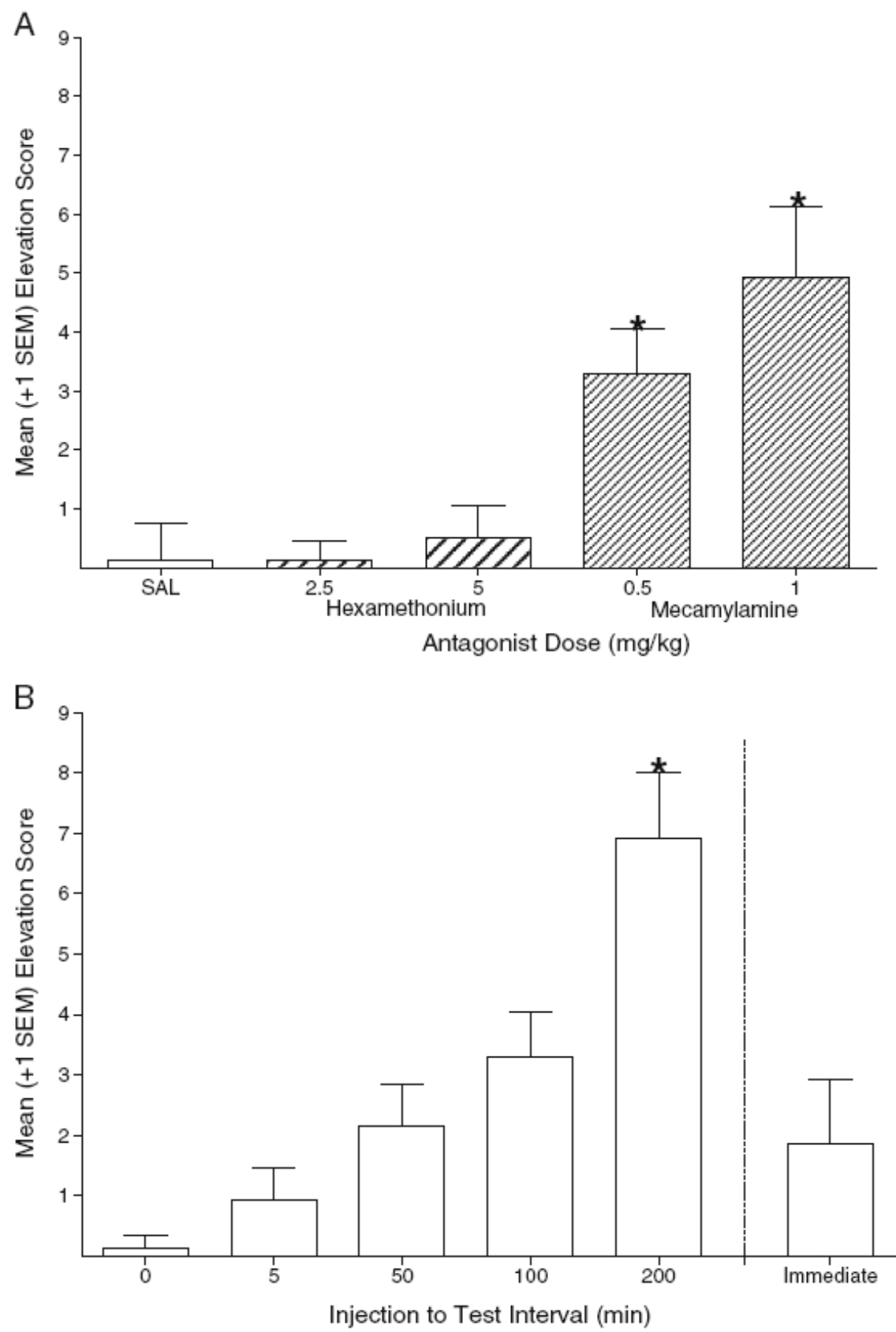
scores at the 5 and $10 \mathrm{mg} / \mathrm{kg}$ bupropion doses were significantly higher than the nicotine comparison $\left(\mathrm{mmd}_{\mathrm{hsd}}=2.73\right)$. Elevation scores for the 10, 20, and $30 \mathrm{mg} / \mathrm{kg}$ bupropion doses were significantly lower than saline. The $\mathrm{ED}_{50}$ for bupropion was $12.5 \mathrm{mg} / \mathrm{kg}$. The ANOVA for arecoline was not significant $[F(2,24)=2.39, p=0.113$; Fig. $4 b]$. Given the trend, this lack of effect was likely driven by the variability at the $0.375-\mathrm{mg} / \mathrm{kg}$ dose. The higher dose of CDP appeared to partially substitute for the nicotine feature $[F(2,24)=7.36$, $p=0.003$, MSE $=6.15]$. Goal tracking to all doses of CDP was significantly higher than nicotine $\left(\mathrm{mmd}_{\mathrm{hsd}}=2.46\right)$. However, only the $10-\mathrm{mg} / \mathrm{kg}$ dose was significantly lower than saline. We did not calculate an $\mathrm{ED}_{50}$ for $\mathrm{CDP}$ given that full substitution was not demonstrated. Caffeine $(5-30 \mathrm{mg} / \mathrm{kg})$ did not substitute for the nicotine feature $(F<1)$. Dipper entries during the pre-CS period were not significantly altered by any of the drugs $(F$ 's $<1.6$; Table 2$)$.

Locomotor assessment Relative to saline, nicotine $(0.2$ and $0.4 \mathrm{mg} / \mathrm{kg})$ and caffeine $(10$ and $30 \mathrm{mg} / \mathrm{kg}) \mathrm{did}$ not affect activity ( $p$ 's $\geq 0.23$; see Fig. 5 ). In contrast, amphetamine $(1 \mathrm{mg} / \mathrm{kg})$ and bupropion $(20 \mathrm{mg} / \mathrm{kg})$ significantly increased activity above saline levels $[t$ 's $(12) \geq 5.08$, $p$ 's $<0.001]$. CDP $(10 \mathrm{mg} / \mathrm{kg})$ and both doses of arecoline $(0.75$ and $1.5 \mathrm{mg} / \mathrm{kg}$ ) had locomotor suppressant effects $(t$ 's $>2.54, p$ 's $<0.03)$.
Fig. 4 a Mean elevation score $( \pm I$ SEM) for the nicotine generalization tests from rats in group 2. Asterisks denote significant difference $(p<0.05)$ from the training dose of nicotine $(0.4 \mathrm{mg} / \mathrm{kg})$. Plus indicates a significant difference from saline (SAL). b Mean elevation scores from the substitution tests for group 2. The upper solid line represents the average elevation score from the last saline session before the start of substitution testing. Dashed lines represent the SEM. Plus symbols indicate a significant difference from this saline comparison. The lower solid line represents the average elevation score from the last nicotine session before the start of substitution testing. Dashed lines represent the SEM. Asterisks indicate a significant difference from this nicotine comparison. These post hoc comparisons were only conducted if the overall ANOVA was significant
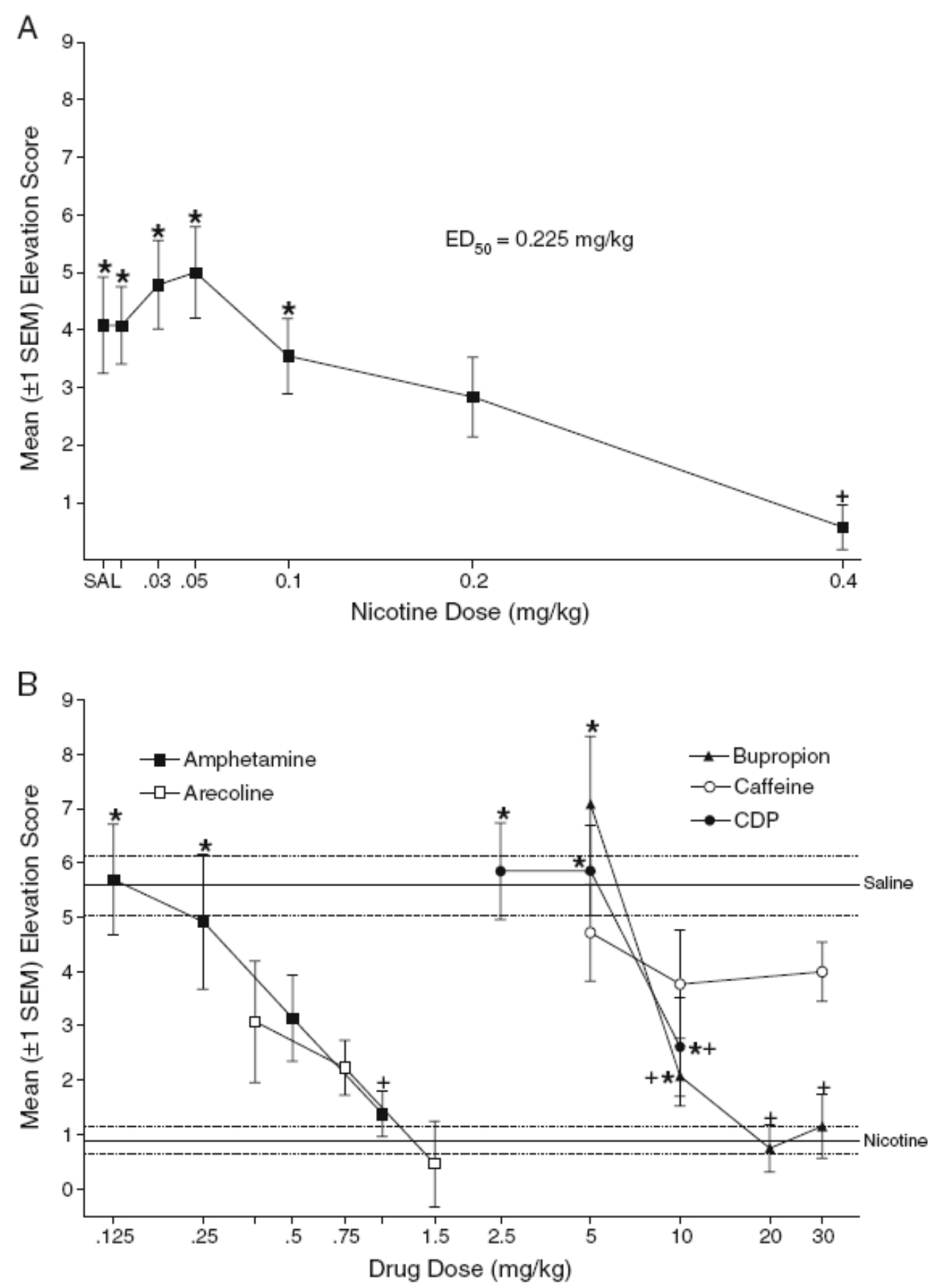
Table 2 Pre-CS and CS dipper entries ( \pm 1 SEM) for group 2

\begin{tabular}{llllllll}
\hline \multicolumn{2}{c}{ Nicotine Generalization $(\mathrm{mg} / \mathrm{kg})$} \\
Pre-CS & Saline & 0.01 & 0.03 & 0.05 & 0.1 & 0.2 & 0.4 \\
\cline { 2 - 8 } CS & $1.57( \pm .39)$ & $1.14( \pm .31)$ & $0.93( \pm .20)$ & $0.86( \pm .23)$ & $1.14( \pm .29)$ & $0.79( \pm .19)$ & $0.93( \pm .16)$ \\
& $5.07( \pm .74)$ & $5.43( \pm .60)$ & $5.71( \pm .79)$ & $5.29( \pm .80)$ & $3.79( \pm .57)$ & $3.29( \pm .62)$ & $1.50( \pm .33)$
\end{tabular}

Substitution Testing

Amphetamine ( $\mathrm{mg} / \mathrm{kg}$ )

\begin{tabular}{lllll} 
& 0.125 & 0.25 & 0.5 & 1.0 \\
\cline { 2 - 5 } Pre-CS & $0.77( \pm .23)$ & $0.69( \pm .24)$ & $0.31( \pm .13)$ & $0.54( \pm .24)$ \\
CS & $6.46( \pm .95)$ & $5.62( \pm 1.04)$ & $3.50( \pm .76)$ & $1.92( \pm .37)$
\end{tabular}

Arecoline $(\mathrm{mg} / \mathrm{kg})$

$\begin{array}{llll} & \underline{0.375} & 0.75 & 1.5 \\ \text { Pre-CS } & 0.62( \pm .27) & 0.15( \pm .10) & 0.77( \pm .32) \\ \text { CS } & 4.31( \pm .95) & 2.15( \pm 1.04) & 1.62( \pm .76)\end{array}$

Bupropion $(\mathrm{mg} / \mathrm{kg})$

$\begin{array}{lllll} & 5.0 & 10.0 & 20.0 & 30.0 \\ \text { Pre-CS } & 0.31( \pm .17) & 0.54( \pm .24) & 1.00( \pm .53) & 0.85( \pm .39) \\ \text { CS } & 7.23( \pm 1.20) & 2.85( \pm .65) & 1.77( \pm .48) & 2.00( \pm .51)\end{array}$

Caffeine $(\mathrm{mg} / \mathrm{kg})$

$\begin{array}{llll} & 5.0 & 10.0 & 30.0 \\ \text { Pre-CS } & 0.92( \pm .21) & 0.92( \pm .26) & 0.62( \pm .18) \\ \text { CS } & 5.71( \pm .87) & 4.69( \pm .89) & 4.62( \pm .55)\end{array}$

$\mathrm{CDP}(\mathrm{mg} / \mathrm{kg})$

$\begin{array}{llll} & \underline{2.5} & 5.0 & 10.0 \\ \text { Pre-CS } & 0.92( \pm .31) & 0.92( \pm .39) & 0.54( \pm .31) \\ \text { CS } & 6.69( \pm .86) & 6.71( \pm .62) & 3.15( \pm .82)\end{array}$

Fig. 5 Mean activity ( \pm I SEM) from the locomotor test for higher doses of ligands used during substitution testing. The average for the saline (Sal) condition includes the 19 rats tested with saline. However, the 12 rats tested with $0.4 \mathrm{mg} / \mathrm{kg}$ nicotine, $\quad \mathrm{I} \mathrm{mg} / \mathrm{kg}$ amphetamine (Amp), $20 \mathrm{mg} /$ $\mathrm{kg}$ bupropion (Bup), $10 \mathrm{mg} /$ $\mathrm{kg}$ chlordiazepoxide (CDP), and $1.5 \mathrm{mg} / \mathrm{kg}$ arecoline were compared only to their activity with saline (i.e., paired $t$ tests). Similarly, the seven rats tested with $0.2 \mathrm{mg} / \mathrm{kg}$ nicotine, 10 and $30 \mathrm{mg} / \mathrm{kg}$ caffeine, and $0.75 \mathrm{mg} / \mathrm{kg}$ arecoline were compared only to their saline activity. Each rat remained at its $85 \%$ weight and was assigned a unique drug order for testing. Asterisks denote significant difference from its saline comparison, $p<0.05$

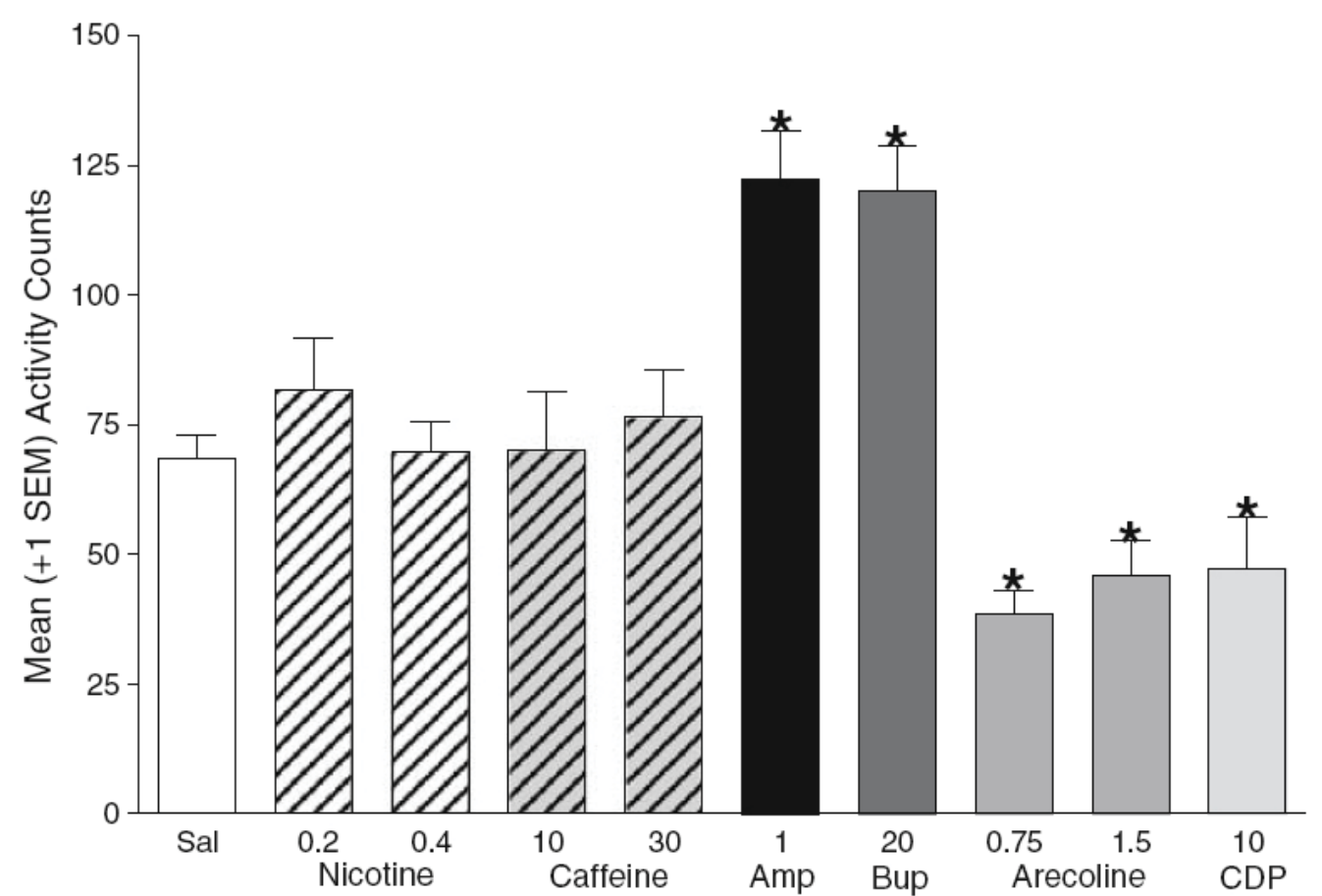

Test Drug and Dose $(\mathrm{mg} / \mathrm{kg}$ ) 


\section{Discussion}

There are numerous demonstrations that exteroceptive stimuli such as a light or tone can serve as negative features in an appetitive discrimination task (e.g., Holland 1984; Rescorla 1989). Recently, Troisi and Akins (2004), using a sexual conditioning task, extended this observation to an interceptive drug cue (cocaine) in male quail. The present study extends this research to rats with nicotine $(0.4 \mathrm{mg} / \mathrm{kg})$ as the negative feature. That is, the goal-tracking CR during the light CS was inhibited on nicotine sessions. This extension also includes a different appetitive US, as well as use of a continuous-trial procedure rather than a discrete-trial procedure. This latter feature has the advantage of allowing several presentations of the US and/or the CS in a single placement into the apparatus.

The finding that nicotine functions as a negative feature extends our previous research with nicotine as positive feature (Palmatier et al. 2004, 2005; Sanderson et al. 2003). As a positive feature, nicotine signals light CS-sucrose US pairings; saline signals nonreinforcement of the CS. We took nicotine's control of goal tracking as evidence that nicotine functioned as a positive feature. Alternatively, an unconditional effect of nicotine might have increased dipper entries during the light CS. This account assumes that the light is mildly excitatory from sucrose delivery on $50 \%$ of the presentations and that nicotine acts on this excitation to increase dipper entries. Previously, our enthusiasm for this account was decreased by the failure of amphetamine to substitute for the positive nicotine feature (Palmatier et al. 2005). The present study provides direct evidence against this unconditional effect account in that sucrose was still delivered on $50 \%$ of the light presentations, yet dipper entries to the light CS on nicotine sessions were very low. Conversely, nicotine has been shown to affect ingestive behaviors (e.g., Baettig et al. 1980). The previous feature positive research with nicotine strains an appetite suppression account of response inhibition for nicotine as a negative feature. That is, as a positive feature, nicotine prompted robust sucrose-seeking behavior even on the first light presentation of the session-before sucrose delivery (see Sanderson et al. 2003, Fig. 3b).

Pretreatment with the central and peripheral nAChR antagonist mecamylamine restored the goal-tracking $\mathrm{CR}$ to the light CS on nicotine test sessions; hexamethonium, a peripheral $\mathrm{nAChR}$ antagonist, did not. This outcome suggests a role for central nervous system (CNS) nAChRs. The cueing effects of nicotine, whether in a Pavlovian or operant procedure, appear to be mediated by central nAChRs. Previous research has shown a similar pattern of antagonism when nicotine served as a positive feature (Palmatier et al. 2004), as a CS+ or CS- (Besheer et al. 2004), or as an $S^{D}$ (Stolerman et al. 1984). Nicotine as a negative feature also varied with time since administration. Goal tracking to the light CS increased as injection to test interval increased to $200 \mathrm{~min}$. Loss of stimulus control with delays between 100 and $200 \mathrm{~min}$ is similar to research with nicotine as an $\mathrm{S}^{\mathrm{D}}$ (Hirschhorn and Rosecrans 1974; Schechter and Meehan 1992), a CS+ (Besheer et al. 2004), or a positive feature (Palmatier et al. 2004). This result likely reflects decreased brain levels of nicotine (Ghosheh et al. 1999) and is consistent with the conclusion that CNS processes mediate nicotine's ability to serve as a negative feature. One surprising result poses a caveat to this conclusion. In general, when the cueing effects of nicotine are tested within 2-3 min after administration, there is a loss of stimulus control (Besheer et al. 2004; Palmatier et al. 2004; Pratt et al. 1983). This outcome is often attributed to insufficient brain levels of nicotine (cf. Pratt et al. 1983). We did not find this result in the present study. This suggests a possible peripheral component to nicotine as a negative feature. Notably, in previous research showing a loss of stimulus control, nicotine signaled availability of the reinforcer/US. In the present research, nicotine signals the absence of the US. Whether this difference is important will require establishing temporal-delay functions for nicotine as a CS- and as an $\mathrm{S}^{\Delta}$.

Conditional control by the negative nicotine feature was highly sensitive to shifts from the training dose $(0.4 \mathrm{mg} /$ $\mathrm{kg}$ ). When rats were tested with the $0.1-\mathrm{mg} / \mathrm{kg}$ dose of nicotine, goal tracking to the light CS was comparable to saline levels. This sensitivity was also reflected in an $\mathrm{ED}_{50}$ of $0.225 \mathrm{mg} / \mathrm{kg}$. This value is high relative to other discrimination procedures: drug discrimination research using lever pressing (Chance et al. 1977, $\mathrm{ED}_{50}=0.087 \mathrm{mg} / \mathrm{kg}$; Pratt et al. $1983, \mathrm{ED}_{50}=0.14 \mathrm{mg} / \mathrm{kg}$ ), Pavlovian feature positive for an appetitive CS-US relation (Palmatier et al. 2005, $\mathrm{ED}_{50}=0.054 \mathrm{mg} / \mathrm{kg}$ ), and Pavlovian conditioning with nicotine as the $\mathrm{CS}+\left(\right.$ Besheer et al. $\left.2004, \mathrm{ED}_{50}=0.113 \mathrm{mg} / \mathrm{kg}\right)$. As suggested earlier, perhaps this difference reflects nicotine serving as a signal for the absence of the reinforcer vs a signal for its presence.

The ability of nicotine to serve as a negative feature was not based on a nonspecific presence of drug vs absence of drug discrimination. If so, the discriminable $0.1 \mathrm{mg} / \mathrm{kg}$ nicotine dose would have maintained stimulus control (Bevins and Palmatier 2004; Stolerman et al. 1984). Also, caffeine at 10 - and $30-\mathrm{mg} / \mathrm{kg}$ doses shown to have $\mathrm{S}^{\mathrm{D}}$ effects (Mumford and Holtzman 1991) would have substituted for the nicotine feature. Neither result occurred. There is the possibility, however, that a higher dose of caffeine might substitute for nicotine in the present study. Mumford and Holtzman (1991) found that acquisition of an operant discrimination was faster with 56 than $10 \mathrm{mg} / \mathrm{kg}$ of caffeine; the pattern of substitution also differed between these doses suggesting different discriminative properties.

In contrast to caffeine, amphetamine, bupropion, arecoline, and CDP produced a loss of goal tracking during the light CS. Albeit suggestive of substitution, interpretation of this data pattern was complicated by the locomotor effects of the ligands. CDP (10 mg/kg) and arecoline (0.75 and 
$1.5 \mathrm{mg} / \mathrm{kg}$ ) suppressed general activity. Thus, the decrease in CR to the light CS more likely reflects suppression of activity than shared stimulus properties with nicotine. In future experiments, it will be of interest to test whether repeated administration of these locomotor suppressing ligands produces differential tolerance for the locomotor vs the negative feature effects of these ligands.

Previous research with nicotine as a CS+ or as an $\mathrm{S}^{\mathrm{D}}$ has reported partial and/or full substitution with bupropion and amphetamine (Besheer et al. 2004; Chance et al. 1977; Young and Glennon 2002). For example, when nicotine served as a CS+, bupropion $(20 \mathrm{mg} / \mathrm{kg})$ evoked conditioned responding that was about $80 \%$ of that controlled by the $0.4 \mathrm{mg} / \mathrm{kg}$ nicotine training dose (Besheer et al. 2004). Substitution in that research was evidenced by an increase in goal tracking, whereas substitution for the negative nicotine feature in the present research was evidenced by a decrease in CR. This analysis suggests that the loss of CR to amphetamine and bupropion in the present research reflects shared stimulus properties with the nicotine feature. However, we cannot eliminate the possibility that the increase in activity seen in the locomotor assay for amphetamine and bupropion did not interfere with dipper entries during substitution.

One other finding from the locomotor assay deserves discussion. In our hands, repeated exposure to nicotine (0.18$0.42 \mathrm{mg} / \mathrm{kg}$ ) increases rat's locomotor activity relative to saline - even in the first 5 min (Bevins and Palmatier 2003; Bevins et al. 2005). This increase in activity was not seen at the $0.2-$ or $0.4-\mathrm{mg} / \mathrm{kg}$ dose in the present experiment. The most likely reason for this difference is the degree of chronic experience with nicotine. The research showing locomotor activation to nicotine tends to expose rats once per day for 8-10 days. In contrast, the rats in the present experiment were exposed to the training dose of nicotine at least 77 times. In support of this interpretation, rats pre-exposed to nicotine $(0.18$ or $0.42 \mathrm{mg} / \mathrm{kg})$ for only 27 days in the home cage had inflated activity levels when subsequently treated with saline and tested in the same locomotor chambers used in the present experiment (Bevins and Palmatier 2003).

Interpretation of the substitution test results is complicated by the fact that motor alterations (e.g., suppression, stereotypy) and substitution for nicotine as a negative feature have the same data pattern-withholding of goal tracking. Dipper entries during the pre-CS period were so low (ca. 1 per $15 \mathrm{~s}$ ) that it does not provide a useful index of motor impairment. Also, locomotor activation on this baseline was not seen to amphetamine or bupropion. Soon, the chambers will be fitted with infrared beams so that we also have a measure of motor activity. Perhaps this will help dissociate motor effects from substitution via shared stimulus properties. Until such time, we prefer this conservative and more parsimonious locomotor interpretation. That is, considering the ligands tested in substitution act on diverse neural processes (e.g., muscarinic acetylcholine receptor agonist, a $\mathrm{GABA}_{\mathrm{A}}$ agonist, dopamine and norepinephrine reuptake in- hibitor, and dopamine agonist), one would be stretched to hypothesize a common neural process for substitution.

The present feature negative protocol will be useful in elucidating the associative processes by which nicotine may inhibit conditioned responding. In more widely studied Pavlovian discrimination tasks, there have been numerous models suggested for these underlying inhibitory processes (Bouton and Nelson 1998; Brandon and Wagner 1998; Holland 1992; Swartzentruber 1995). Figure 6 presents just two possible models. Conditioned responding in both models is the result of an excitatory association between light CS and sucrose US. Model 1, however, suggests that the negative nicotine feature alters the neurobiological processes mediating the US representation. Rescorla (1979) described this inhibitory input as decreasing the ability of an excitatory CS to activate US processes (see Konorski 1948). Thus, the nicotine feature attenuates conditioned responding to the light because of a decreased "US threshold" for activation. Notably, this model predicts that the nicotine feature should pass retardation and summation tests of conditioned inhibition (Rescorla 1969, 1979). In the retardation test, nicotine would be paired with the US after it was established as a negative feature; acquisition of conditioned responding to nicotine as a CS+ should be slower (retarded) relative to controls. In the summation test, nicotine's ability to inhibit a CR should transfer to any excitatory CS that was paired with a comparable appetitive US.

Model 2, in contrast, assumes that nonreinforcement (i.e., extinction) of the light CS in nicotine sessions results in an inhibitory association with the US. However, the inhibitory association is conditional. This conditionality reflects the observation that original excitatory training generally transfers to different contexts, yet extinction of that CS tends to be specific to the extinction context (Bouton and King 1983). Accordingly, model 2 includes an "and gate" (hatched circle) so that the inhibitory CS-US association does not affect conditioned responding unless the nicotine feature is present (see Bouton and Nelson 1998 for related details).
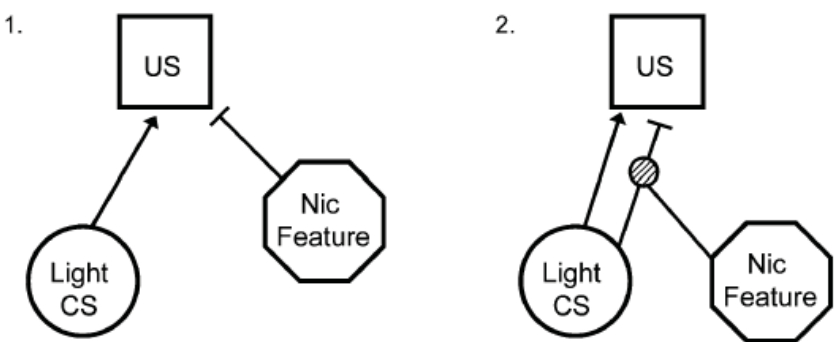

Fig. 6 Two possible models of how the nicotine feature could inhibit conditioned responding to the light CS. Models and graphic representation based on writings from Bouton and Nelson (1998), Holland (1992), and Rescorla (1979). An arrow denotes excitatory association, whereas a line with crossbar indicates an inhibitory association. Hatched circle denotes an "and gate" allowing conditional operation of the inhibitory association by the nicotine feature. 
Importantly, the two models make some distinct predictions. One notable prediction has to do with the retardation test described previously. In contrast to model 1, model 2 does not necessarily predict slower acquisition of conditioned responding to the nicotine feature if it is paired with the US after being trained as a negative feature. Another, and perhaps even more interesting, is that nicotine in model 2 would retain its ability to serve as a negative feature for the light CS after this excitatory conditioning. Note that in model 2, an added excitatory association between nicotine and the US does not alter nicotine's action on the inhibitory light CS-US association. In contrast, depending on theoretical perspective, subsequent excitatory training of the nicotine feature in model 1 would either result in a separate excitatory association with the US or it would abolish and replace the nicotine-US inhibitory association with an excitatory association. Regardless, both predict significant loss of nicotine's ability to serve as a negative feature.

We do not mean to imply in this closing discussion that the two models presented in Fig. 6 are the only possible inhibitory mechanisms. For example, nicotine could be acting on the CS-US association (Holland 1992) or it could be part of a distinct configural cue (Pearce 1987). Rather, our point was to demonstrate the likely utility of this negative feature task and associated theorizing in leading to novel experiments elucidating a potential inhibitory mechanism by which nicotine and other drugs of abuse (cf. Troisi and Akins 2004) might operate. Indeed, relative to other conditioning processes, inhibitory learning processes have been essentially ignored in the drug conditioning field.

Acknowledgements: We thank Chana Akins, Joe Ayres, and Jennifer Murray for their thoughtful comments on an earlier version of this report. The research and R.A. Bevins were partially supported by United States Public Health Service grants DA011893 and DA018114. M. I. Palmatier was supported by USPHS grant DA06092 while conducting this research.

\section{References}

Asghar K, Roth LJ (1971) Entry and distribution of hexamethonium in the central nervous system. Biochem Pharmacol 20:2787-2795

Baettig K, Martin JR, Classen W (1980) Nicotine and amphetamine: differential tolerance and no cross tolerance for ingestive effects. Pharmacol Biochem Behav 12:107-111

Besheer J, Palmatier MI, Metschke DM, Bevins RA (2004) Nicotine as a signal for the presence or absence of sucrose reward: a Pavlovian drug appetitive conditioning preparation in rats. Psychopharmacology 172:108-117

Bevins RA, Palmatier MI (2003) Nicotine-conditioned locomotor sensitization in rats: assessment of the US-preexposure effect. Behav Brain Res 143:65-74
Bevins RA, Palmatier MI (2004) Extending the role of associative learning processes in nicotine addiction. Behav Cogn Neurosci Rev 3:143-158

Bevins RA, Eurek S, Besheer J (2005) Timing of conditioned response in a nicotine locomotor conditioning preparation: manipulations of the temporal arrangement between context cues and drug administration. Behav Brain Res 159:135-143

Boakes RA (1977) Performance on learning to associate a stimulus with positive reinforcement. In: Davis H, Hurwitz HMB (eds) Operant-Pavlovian interactions. Lawrence Erlbaum Associates, Hillsdale, NJ, pp 67-101

Bouton ME, King DA (1983) Contextual control of the extinction of conditioned fear: tests for the associative value of the context. J Exp Psychol Anim Behav Processes 9:248-265

Bouton ME, Nelson JB (1998) Mechanisms of feature-positive and feature-negative discrimination learning in an appetitive conditioning paradigm. In: Schmajuk NA, Holland PC (eds) Occasion setting: associative learning and cognition in animals. American Psychological Association, Washington, DC, pp 69-112

Bouton ME, Sunsay C (2003) Importance of trial versus accumulating time across trials in partially reinforced appetitive conditioning. J Exp Psychol Anim Behav Processes 29:62-77

Brandon SE, Wagner AR (1998) Occasion setting: influences of conditioned emotional responses and configural cues. In: Schmajuk NA, Holland PC (eds) Occasion setting: associative learning and cognition in animals. American Psychological Association, Washington, DC, pp 343-382

Chance WT, Murfin D, Krynock GM, Rosecrans JA (1977) A description of the nicotine stimulus and tests of its generalization to amphetamine. Psychopharmacology 55:19-26

Colpaert FC (1986) Drug discrimination: behavioral, pharmacological, and molecular mechanisms of discriminative drug effects. In: Golberg SR, Stolerman IP (eds) Behavioral analysis of drug dependence. Academic, New York, pp 161-193

Davidson TL, Aparicio J, Rescorla RA (1988) Transfer between Pavlovian facilitators and instrumental discriminative stimuli. Anim Learn Behav 16:285-291

Delamater AR (1995) Outcome-selective effects of intertrial reinforcement in a Pavlovian appetitive conditioning paradigm with rats. Anim Learn Behav 23:31-39

Farwell BJ, Ayres JJB (1979) Stimulus-reinforcer and response-reinforcer relations in the control of conditioned appetitive headpoking ("goal tracking") in rats. Learn Motiv 10:295-312

Ghosheh O, Dwoskin LP, Li W-K, Crooks PA (1999) Residence times and half-lives of nicotine metabolites in rat brain after acute peripheral administration of [2'-14C]nicotine. Drug Metab Dispos 27:1448-1455

Hirschhorn ID, Rosecrans JA (1974) Studies on the time course and the effect of cholinergic and adrenergic receptor blockers on the stimulus effects of nicotine. Psychopharmacologia 40:109-120

Holland PC (1984) Differential effects of reinforcement of an inhibitory feature after serial and simultaneous feature negative discrimination training. J Exp Psychol Anim Behav Processes $10: 461-475$ 
Holland PC (1992) Occasion setting in Pavlovian conditioning. In: Medin DL (ed) The psychology of learning and motivation, vol. 28. Academic, San Diego, CA, pp 69-125

Honig WK, Boneau CA, Burstein KR, Pennypacker HS (1963) Positive and negative generalization gradients obtained after equivalent training conditions. J Comp Physiol Psychol $56: 111-116$

Jaeger TV, Mucha RF (1990) A taste aversion model of drug discrimination learning: training drug and condition influence rate of learning, sensitivity and drug specificity. Psychopharmacology 100:145-150

Konorski J (1948) Conditioned reflexes and neuron organization. Cambridge University Press, Cambridge

Maes JHR, Vossen JMH (1997) Conditional control by midazolam and amphetamine in a rapid appetitive discrimination procedure. Eur J Pharmacol 319:5-11

Martin BR, Onaivi ES, Martin TJ (1989) What is the nature of mecamylamine's antagonism of the central effects of nicotine? Biochem Pharmacol 38:3391-3397

Miller MA, Parker BK, Keely JP, Johnson JL, Schaal DW (2002) Searching for evidence of transfer between drug facilitators. Learn Motiv 33:197-229

Mumford GK, Holtzman SG (1991) Qualitative differences in the discriminative stimulus effects of low and high doses of caffeine in the rat. J Pharmacol Exp Ther 258:857-865

Palmatier MI, Peterson JL, Wilkinson JL, Bevins RA (2004) Nicotine serves as a feature-positive modulator of Pavlovian appetitive conditioning in rats. Behav Pharmacol 15:183-194

Palmatier MI, Wilkinson JL, Bevins RA (2005) Stimulus properties of nicotine, amphetamine, and chlordiazepoxide as positive features in a Pavlovian appetitive discrimination task in rats. Neuropsychopharmacology 30:731-741

Parker BK, Schaal DW, Miller M (1994) Drug discrimination using a Pavlovian conditional discrimination paradigm in pigeons. Pharmacol Biochem Behav 49:955-960

Pearce JM (1987) A model of stimulus generalization for Pavlovian conditioning. Psychol Rev 94:61-73

Pratt JA, Stolerman IP, Garcha HS, Giardini V, Feyerabend C (1983) Discriminative stimulus properties of nicotine: further evidence for mediation at a cholinergic receptor. Psychopharmacology 81:54-60
Rescorla RA (1969) Pavlovian conditioned inhibition. Psychol Bull 72:77-94

Rescorla RA (1979) Conditioned inhibition and extinction. In: Dickinson A, Boakes RA (eds) Mechanisms of learning and motivation. Lawrence Erlbaum Associates, Hillsdale, NJ, pp 83-110

Rescorla RA (1989) Simultaneous and sequential conditioned inhibition in autoshaping. Q J Exp Psychol 41B:275-286

Rescorla RA (1999) Learning about qualitatively different outcomes during a blocking procedure. Anim Learn Behav $27: 140-151$

Sanderson SD, Vennerstrom JL, Cheruku SR, Padmanilayam MP, Thiele GM, Palmatier MI, Bevins RA (2003) Active immunization against nicotine with a peptide vaccine composed of a conformationally biased agonist of $\mathrm{C} 5 \mathrm{a}$ as a molecular adjuvant. Int Immunopharmacol 3:137-146

Schechter MD, Meehan SM (1992) Further evidence for the mechanisms that may mediate nicotine discrimination. Pharmacol Biochem Behav 41:807-812

Schechter MD, Rosecrans JA (1972) Nicotine as a discriminative cue in rats: Inability of related drugs to produce nicotine-like cueing effects. Psychopharmacologia 27:379-387

Stolerman IP (1989) Discriminative stimulus effects of nicotine in rats trained under different schedules of reinforcement. Psychopharmacology 97:131-138

Stolerman IP, Garcha HS, Pratt JA, Kumar R (1984) Role of training dose in discrimination of nicotine and related compounds by rats. Psychopharmacology 84:413-419

Swartzentruber D (1995) Modulatory mechanisms in Pavlovian conditioning. Anim Learn Behav 23:123-143

Troisi JR II (2003) Spontaneous recovery during, but not following, extinction of the discriminative stimulus effects of nicotine in rats: re-instatement of stimulus control. Psychol Rec $53: 579-592$

Troisi JR II, Akins C (2004) The discriminative stimulus effects of cocaine in a Pavlovian sexual approach paradigm in male Japanese quail. Exp Clin Psychopharmacol 12:237-242

Young R, Glennon RA (2002) Nicotine and bupropion share a similar discriminative stimulus effect. Eur J Pharmacol 443:113118 